\title{
Smart learning environments, and not so smart learning environments: a systems view
}

\author{
Jon Dron(D)
}

Correspondence: jond@athabascau.ca

Athabasca University, 1 University Drive, Athabasca, AB T9S 3A3,

Canada

\begin{abstract}
It is fruitless to talk of smart learning environments unless we know what is meant by those that are not smart. All environments influence behaviour and, by and large, are in turn influenced by the behaviour of the agents of which they are at least partially comprised. If there were such thing as a neutral learning environment it would support all forms of learning of any skill or knowledge equally well which, manifestly, none do. In this paper, I will argue that most in-person learning environments tend to encourage some kinds of counter-productive behaviours and are thus, at a systems level, positively stupid. While we may, with care, time, and ingenuity in our teaching, overcome some of the worst consequences, the costs and stresses caused by doing so are high. Much of the skill of contemporary teaching, and of the smart learning environments we create, is concerned with compensating for problems that are almost entirely caused by the environments in which we teach. Our online learning environments have often replicated and even magnified such stupidity, mainly through focusing on the contingent trappings of in-person teaching rather than the problems that those trappings were originally designed to solve. I go on to consider smartness as an emergent attribute arising out of the interplay of structural and dynamic elements in a learning environment, the most significant of which (especially in an online context) being its creative, independent, and motivated human participants. I will discuss ways in which we can orchestrate systems to create the conditions for (but not necessarily to entail) learning environments that can truly be described as 'smart'.
\end{abstract}

Keywords: Learning, Environment, Technology, Learning technology, Smart learning environment, Education, Ecosystem, Complex system

\section{Introduction}

Common definitions of smart learning environments focus on the tools (and, occasionally, the techniques) that are found within them or of which they are constituted. In this paper I will instead use a functional characterization of smart learning environments as being those that actively nurture learning, however that may be achieved. Any number of environments can actively nurture learning, and the more effectively they achieve that, the smarter they are as learning environments. I will be making a case that some very common learning environments actively inhibit learning and could therefore be described as positively stupid. I do

(c) The Author(s). 2018 Open Access This article is distributed under the terms of the Creative Commons Attribution 4.0 International License (http://creativecommons.org/licenses/by/4.0/), which permits unrestricted use, distribution, and reproduction in any medium, provided you give appropriate credit to the original author(s) and the source, provide a link to the Creative Commons license, and indicate if changes were made. 
not mean by this that they are not smart, nor that they are dumb: a dumb learning environment simply offloads the intelligence required for learning onto its inhabitants, the learners and teachers. Indeed, if we assume (as I believe we must) that learners and teachers are not just inhabitants of environments but active parts of them, it is fair to say that there is no such thing as a not-smart or dumb learning environment. There are just differing degrees of smartness found in different parts of the environment and the overall environment itself still leads to learning. However, if the learning environment (including the people, tools, systems, and structures within it) prevents learning, it is hard to think of a better way to characterize it than as 'stupid'. In this I follow the lead of (Cipolla, 2011) in identifying stupid behaviour as intelligent behaviour that serves a harmful purpose. This perspective takes the focus away from the individual components and highlights instead what the entire system achieves.

I will be making the point that, in principle, an environment's smartness may have little to do with the intelligence of any of its individual parts, any more than the wisdom of a brain is related to the wisdom of its neurons, or than, without further organization and purpose, a random collection of professors is any smarter than a random collection of cats. What makes an environment smart, not-smart, or stupid is, primarily, the configuration of its parts - human and others - and their interactions. Smartness, however, is a matter of perspective: what is smart for one may not necessarily be smart for another, and competing goals - especially those of credentialing - may lead to quite the opposite of smart learning environments.

\section{Definitions}

Current systems that are commonly described as 'smart learning environments' tend to take one of two general forms. The first, that I characterize as a centralized model, imbues the environment with an active role in both adapting to and shaping the behaviour of its inhabitants (e.g. (Spector, 2014; Hwang, 2014)). Examples such as intelligent tutoring systems, adaptive hypermedia, and some forms of learning analytics system learn from the behaviours of their users, combined with algorithmic decision-making capacities, in order to shape themselves and the learning experiences of their inhabitants. Most are context-aware, and either adapt to or are designed to work in specific contexts. They may be fully digital, or blend the digital with the physical, and the degree of digital intelligence may vary from simple rule-based systems to deep learning approaches. Often, they make use of mixed reality, or augmented reality technologies that overlay or annotate the physical environment. An archetypal example might be an agent that guides a student around an environment, adapting to their perceived learning and intentions as they proceed (e.g. (Gwo-Jen et al., 2011; Wu et al., 2010; Lu et al., 2011)).

The second form (e.g. (Koper, 2014)) puts more emphasis on independent intelligent objects that to add dynamic behaviours to an otherwise mainly static environment. I describe this as a distributed model, and it is typically found in applications of ambient intelligence (Raisinghani et al., 2006) and ubiquitous/pervasive computing environments (Weiser et al., 1999). An archetypal example might be the use of tags (eg. 2D barcodes or NFC chips) in museums or art galleries that allow suitably equipped learners to delve more deeply into the objects they are viewing. Like the first form, they may sometimes make use of mixed reality or 
augmented reality technologies, or they may make objects themselves into dynamic agents. This form concerns the embedding of active and typically interconnected computer-enhanced objects within a physical environment, rather than making an attempt to transform perceptions of, or strongly control behaviour within, the environment itself. There may be many such objects within an environment, not necessarily aware of or connected to one another.

Centralized and distributed models differ mainly in emphasis rather than kind. The centralized model focuses more on the orchestration of behaviour in the environment taken as a whole, the distributed model more on augmenting the environment with smart components in a bottom-up, piecemeal manner. Many systems blend both models. Both treat the smartness as primarily emerging from digital tools, that adapt and learn in order to improve learning for their inhabitants. Both allow that environments can be virtual, or a blend of virtual and physical, and both treat smartness as a feature of a tool or tools within the environment, rather than the environment as a whole.

Both centralized and decentralized models suffer from the flaw that the presence of smartness within an environment does not necessarily or even normally lead to smartness of that environment. A random crowd of smart people in a street is rarely smart in itself for instance. Both models confuse the environment (the physical, virtual, social context in which learners learn) and the tools and other systems within that environment. Also, both tend to see learning as the achievement of specified learning goals, rather than a complex conversational process that can and usually does lead to much that is of value beyond what is planned. Few provide the means to learn from the learners, apart from in predefined ways.

While some environments may appear to be easily identifiable, it is often difficult to choose where to draw system boundaries. For example, is a learning management system an environment in itself (yes) or part of a broader learning environment that includes the institution to which it is attached (also yes)? Is a learner part of the learning environment or an inhabitant of it, or both? What about the learner's own physical and virtual surroundings?

\section{A third way}

Another way of thinking about smart learning environments is to consider smartness as an emergent consequence of dynamic interactions between the environment's constituent parts, including those of its human inhabitants and the artefacts and structures they wittingly or unwittingly create. In such an environment, as in human brains, smartness emerges as a result of structure and interaction, whether or not either aspect is mediated or enacted through digital technologies. None of the smartness need be programmed as a behaviour of digital tools. It may simply be due to the structure that is available (which may be partly or wholly designed), combined with the presence of the learner and one or more other people, and their activities with relation to one another. Whether the parts are designed, emergent, or simply found, and no matter who or what performs the orchestration of them, it is the whole system that leads to improved learning, and it is at the level of the whole environment that we should look for smartness, not in its parts. With that in mind, most of the rest of this paper is concerned with trying to discover the characteristics of such an environment, and the 
points at which we can most fruitfully intercede to make stupid environments smart, and smart environments smarter.

\section{The smartest learning environment}

Bloom's 2-sigma problem (Bloom, 1984) - the challenge to achieve, through more efficient teaching methods, at least the same 2 sigma difference that is seen between achievements of those taught in conventional classroom settings and those taught via one-to-one tutoring - remains unmet after nearly 35 years of concerted effort. This is not because of any methodological or technical process advantage in one-to-one teaching, but because it provides the smartest learning environment we have yet to invent. One-to-one teaching is the condition under which learning occurs, not the way that teaching is performed. Bloom and many successors have sought to compare it with methods of teaching such as mastery learning, problem-based learning, or active learning, but such comparisons are unfair because the environment's effectiveness is largely because virtually any pedagogical methods can be used, allowing the tutor to adapt very precisely to the needs of the learner in real time, changing pedagogy, pace, topic, and so on as needed. Within a limited domain, a sufficiently smart artificial general intelligence (AGI) might one day adapt as effectively, though none has not yet come close, and realistic extrapolations put AGI at least 30 years away if it ever occurs at all (Goertzel, 2014). Even if it did, a much less easily duplicable benefit is the ease with which a student may establish a relationship with the tutor. This matters. A human tutor may model behaviours, reassure, enthuse, and use emotional responses of many kinds to help guide, engage, and motivate a learner. A human tutor offers companionship. A teacher's compassion and caring, whether expressed in gentle encouragement or even through impatience or annoyance, can be critical to successful learning. While a smart machine might simulate such things for a little while, and it is not that unusual for humans to form something like emotional attachments to machines, for now at least it is hard to imagine that a student would care too much about the feelings of a computer when compared with a real human being, and worrisome that they might (Turkle, 2011).

There are, at first glance, only two elements in the one-to-one tutoring environment. However, all learning environments contain further structural features that can enhance or diminish the effectiveness of this basic configuration. A noisy environment, for example, interferes with the signal so that it may not be heard; a distracting environment overwhelms it with irrelevant signals. Both may justly be described as stupid, inasmuch as, despite the smartness of the central features of the environment, the overall assembly actively interferes with learning. Sometimes, however, a skilled tutor may take advantage of distractions to help make or illustrate a point: an apple falling on the student's head might, for example, provide a useful starting point for a discussion on gravity. Even noise might be useful in some contexts, for example to pause for reflection, or simply to provide effectively spaced learning (Fields, 2005). Such creative responses are, as yet, beyond any AI, because they demand general intelligence emerging from growing up and learning in a community of humans.

Conversely, other environmental features may lead to more effective learning. Sometimes, a bland, evenly lit room at a comfortably temperature with a couple of chairs might be all that is needed to help provide focus. At other times, a walk in the garden, or a meandering voyage on a sailboat might provide the right combinations of 
relaxation, stimulation, exercise, and fresh air needed to spark inspiration and expansive thinking. Both learners and teachers can affect their environment. It makes a difference how they position chairs, what postures they adopt, whether a window is open, where they position themselves in relation to each other, where they choose to meet in the first place, and so on. Each decision makes the overall environment more or less smart for a given learner in a given situation. This also illustrates that, at least when an environment contains other people, every learner's environment is different from that of every other. It is not the same environment to the tutor as it is for the student, because the student is in it, not the one that is experiencing it.

This brief synopsis shows that even an environment as simple as that embodied by one learner and one tutor is always full of vast opportunities for flexibility, and may be adapted by both the learner and the teacher through adding or changing aspects of it. There is a constant interplay between the teacher, the learner, and their surrounding environment (of which they are a part) that, all things being equal, combines to lead to better learning than the learner may have been able to achieve alone. But real learning environments, including through one-to-one tutoring, are vastly more complex than this.

\section{The teaching gestalt}

In almost any learning context, including the most regimented of traditional classrooms as well as one-to-one teaching, there are multiple teachers. Learners themselves are most obviously part of that teaching gestalt, orchestrating what they discover, with the assistance of their teacher, and with what and how they already know. There usually are many other contributors to that gestalt. The authors of textbooks, the designers of the classroom space, the creators of the timetable, the builders of the program, the creators of whiteboards, pens, paper, and the makers of a host of other created artefacts play an important role in the orchestration of phenomena that lead to learning. Even in in-person learning environments we swim in a river of teachers. When the billions of people that form the Internet, combined with the tens of billions of resources they have created, are added to that mix, we swim in an ocean.

All designed environments, and all tools (conceptual as well as physical, procedural as well as embodied) that are part of them, might be seen as at least participants in human intelligence. The things that we and others create are an essential and non-optional part of our own cognition (Pea, 1993; Clark, 2008; Gibson, 1977; Norman, 1991): they embody learning and do not just help us to think, but actively form part of our thinking process. This is implicit in all social-constructivist accounts of learning, and is an explicit cornerstone of connectivist theories that are, arguably, the most significant theories of teaching and learning to have emerged in the past few decades (Dron \& Anderson, 2014). A significant body of research across multiple scholarly fields suggests that our intelligence is fundamentally distributed, between people, and between people and their environment. In this sense, all constructed environments that are inhabited by humans are active contributors to the intelligence both of individuals and of communities of individuals. 'Intelligent', however, is not synonymous with 'smart'. It is possible to be both intelligent and stupid (or, at least, not very intelligent). Smartness implies that such behaviours are not only intelligent but effective to some specific purpose. Digital technologies allow us to embed such purposes within the environment. 


\section{Digital environments}

It is tempting but misleading to think of digital analogues of the classroom environment, such as learning management systems or webinar classes, as learning environments of the same essential kind. In the first place, with the partial exception of fully immersive virtual environments, digital environments only ever form part of the learner's environment, and usually it is only a very small part limited to a two-dimensional screen or, occasionally, a stereo representation of a 3D space. In contrast, physical classrooms and their contents (including people) are, at least for the duration of a lesson, the entire environment in which learning occurs.

In the second place, that screen itself is at most a gesture away from many other environments that are held within it or that can be entered with the click of a mouse or touch of a finger. The one environment of the virtual space is home to very many more that, on the whole, lack an innate geography or fixed relationships with one another. The act of moving between physical environments is not just more palpable, but the transition itself involves interaction with one or more other environments, each of which may contribute to the entire learning experience, as may their configuration relative to one another. Within a specific designed digital space we may represent such connections (e.g. through hyperlinks, clustering, sorting, or graphic signposts) but, in the environment as a whole, they are not innately connected.

Digital devices greatly expand the adjacent possible (Kauffman, 2000), and may therefore greatly enrich our learning environments. Most digital devices are primarily used for communication, and it is possible to consider virtually every transaction involving other people - including emails, accesses to web pages, social media interactions, SMS messages, and so on - as a learning transaction, even if 'all' that we are doing is learning how other people feel, or their reaction to a newsworthy event, or what the weather will be like, or who did what on a soap opera. Every Google search is concerned with seeking knowledge. Virtually all uses of StackExchange, Yahoo Answers, Wikipedia, or any one of thousands of recipe sites, for instance, are in search of knowledge or skills. A learning environment that contains online digital environments vastly enriches that environment but never replaces it, except in the sense that an engrossing book may lead us to block out other things around us.

\section{Technology evolution}

Focus on the digital technologies that mediate (parts of) our learning environments highlights a crucial point that all learning environments are a combination of people and technologies (including structures, rules, methods, tools, machines, mechanisms and so on). Some of those technologies are physical, some virtual, but many of them - from design principles and teaching methods to the application of Roberts Rules in meetings - are partially or wholly enacted by and contained within people. Educational environments are designed, whether by independent, cooperating, or collaborating architects. They are, in essence, technologies for (at least) learning, and they consist of a vast number of parts, many of which are technologies in themselves. Understanding the nature of technologies is therefore central to properly understanding these environments.

Brian Arthur (2009) presents a compelling set of arguments that, firstly, technologies are the orchestration of phenomena to some use and, secondly, that they adapt and 
evolve (in a Darwinian sense) primarily through a process of assembly. Phenomena that might be orchestrated can range from physical characteristics and laws to beliefs about deities or how people learn: pedagogies (methods of teaching) are as much technologies as cog wheels. Significantly, the phenomena that are orchestrated are often provided by other technologies. For example, the characteristics of cog wheels make it possible for them, in assembly, to form parts of a clock, and that clock itself may play a role in a vast range of other technologies from school timetabling to decorating the interior of a car. Such phenomena do not have to be real. As Franklin notes, there are as much technologies of prayer as there are of coal mining (Franklin, 1999). Nor do they need to be true: we may, for instance, base pedagogies (methods of learning) on false beliefs about how people learn, or apply motivational techniques based on an incorrect understanding of motivation.

Drawing on Arthur's analysis and definition of 'technology', and to clarify and extend existing fuzzy and inconsistent definitions of the terms, I have developed a formal distinction between softer and harder technologies (Dron, 2013). Hardness in technologies is a measure of the extent to which the orchestration of phenomena is pre-defined: archetypal examples might include not only factory assembly lines, clocks, or a vehicle engines, but also non-corporeal technologies such as legal systems, meeting procedures, or operating instructions. Softer technologies are those in which more of the orchestration is performed by the user of the technology in order for it to achieve a purpose: archetypal examples might include pencils, language, writing, or knitting, each of which is useless without further orchestration by an individual at the point they are used. There are few, if any, purely hard or purely soft technologies: it is a continuum.

Perspective is critically important, as are the boundaries that we choose to distinguish one technology from another. To a student using it to take an objective test, a computer might be seen as very hard but, to its programmer, it is a very soft technology and, to the preparer of the test, something in between. Though each use may incorporate the exact same physical machinery, and precisely the same software, in each case we are looking at a very different technology, assembling and orchestrating different phenomena, for different purposes. Similarly, pedagogies may be very soft technologies for teachers, but very hard technologies to students suffering them in a lecture theatre. Failure to observe boundaries and perspectives is very common and results in many misleading or spurious consequences, such as misguided attempts to measure the effectiveness of computers in classrooms or to compare the results of online and in-person teaching. It makes no more sense to examine the effectiveness of computers in schools than it does to examine the effectiveness of transistors or screws in classrooms. Just as environments usually contain, are contained by, and connect with other environments, viewed from one perspective a computer is a technology, as are its transistors, the programs that run on it, and the screws that hold it together. From the perspectives that matter, it is merely part of many other technologies. It is essential to look at the entire assembly, not just at a subset of parts, in order to understand it, let alone to design it. It is also important to remember that technologies are designed, and may always be designed (or used) better, so past performance may poorly predict future usefulness. Checkland (quoted in (Checkland, 2000)) explains the central problem:

"Thus, if a reader tells the author 'I have used your methodology and it works', the author will have to reply 'How do you know that better results might not have been 
obtained by an ad hoc approach?' If the assertion is: 'The methodology does not work' the author may reply, ungraciously but with logic, 'How do you know the poor results were not due simply to your incompetence in using the methodology? "(p.114).

Much of the value of harder technologies in a learning context is that they embed thinking so that we don't have to think ourselves. Even when we are capable, we may not be able or willing. A computer programmer may be more than capable of constructing a typical LMS, but it would take much energy, time, and thought for even a highly proficient programmer to build such functionality from scratch. Most programmers would use pre-existing libraries, frameworks, or components to simplify the task, or modify existing open source tools, thus hardening the pieces (delegating some of the thinking to other programmers) but, even then, they would expend far more effort than a typical teacher using a much harder LMS for the same task. As the tools become harder, the tasks they embody become easier to perform but, invariably, at a cost of flexibility. The softer the technology, the more work that is needed to make it work, but the greater the potential for creativity, close adaptation to needs, and more precise problem-solving. Thanks to its technological nature, the same is true of a learning environment. A learning environment that is too hard (from the perspective of the learner) reduces autonomy, and may fail to fit well with a particular learner's needs and interests. One that is too soft may demand too many decisions that the learner may be incompetent or unwilling to make. If the environment were a classroom, there may be little that could be done by the learner, beyond informing the teacher of the problems. For that teacher, or for the learner when in control of their own environment (e.g. when online), it would be useful to know what could be done to make it softer or harder, as needed, to which we turn next.

\section{Making learning environments harder or softer}

Aggregating technologies with an environment without removing what was there previously always softens the overall assembly, because it increases the adjacent possibles within that environment, while not replacing what was already in it (Kauffman, 2000). For instance, if we aggregate a whiteboard with a classroom, there are more ways for a teacher to teach than before we did so, notwithstanding the power of defaults and the increased likelihood that, because it is available, it will be used. Replacement of one part of the environment with another will simply make that part of the system as hard or soft as the replacement. The same is true when the output of one technology provides the input to another, such that they effectively become a single organizational unit: they are chained together so that only the last link in the chain matters, whether softer or harder. For instance, if the results of (softer) teacher notes are converted to (harder) grades that are entered into a system that converts them to (harder) percentages in order to calculate a final mark, which is all the student sees, then the overall system is as hard as the final stage of the process: percentages have effectively replaced feedback. If the teacher's notes are made available as well as the grades or marks, the systems is softer, despite the chaining, because the technologies are effectively aggregated.

Most ways of building environments lead to increasing softness, in which the adjacent possible increases. This is the same rachet that drives natural evolution (Kauffman, 2000), and also the principal dynamic behind the evolution of technologies (Arthur, 2009). The more technologies that are available to be assembled, without extinguishing those that 
came before, the more new possibilities for further technologies exist, and old technologies seldom if ever die (Kelly, 2010). However, it also means that by far the most likely trajectory of any environment, built or natural, is towards greater complexity. Softer technologies demand greater engagement and effort on the part of those that use them. As any manager of technologies will attest, from the individual working with their desktop computer to the director of a large bureaucratic organization, complexity (and associated costs, maintenance, and risk of failure) of a complex system almost invariably increases over time unless actively curtailed. Some talk of this rachet as a technological debt, but it is more accurate to call it a technological price: as our environments evolve, they almost inevitably become more complex, and demand greater effort to maintain and manipulate. In the process they usually become more capable, better adapted and, at least as an overall system, more resilient. That resilience may not be desirable, however, because it is the system that is resilient, in the sense of being resistant to large perturbations, not its parts: the system thus protects itself, which may often be at odds with our purposes. To make things worse, chaining tends to lead to a greater dependencies between what may be crucial parts, making individual pieces more fragile because breakages at any point in the chain may render the whole chain useless. Because the overall environment becomes softer, it relies more on human decision-making, which not only increases effort but increases the likelihood of failure at a fine-grained level. It is also, from the perspective of a learner, not always ideal to be faced with multitudes of possibilities. One of the reasons we read books, take courses, or seek mentors is precisely to reduce the range of possible choices to only those that will be helpful in our learning. The ways in which these choices are made largely constitutes the pedagogies of a learning trajectory.

\section{Distributed, aggregated, and chained pedagogies}

Any learning environment, by definition, must contain pedagogies, if we assume that by 'pedagogies' we mean 'methods of teaching and learning'. Traditionally, we tend to think of pedagogies as applied by some agent labelled as a teacher, whether human or machine. However, with our richer and more precise definition of technologies as assemblies, and recognizing that at least some of that assembly resides in humans, it becomes clear that this is only ever a small part of the total picture. Learners themselves usually play by far the largest role: even the hardest of pedagogies and pedagogical assemblies can be softened when assembled with a learner's own knowledge, perspective, and methods of learning. Equally, pedagogies are often embedded or enacted in the harder technologies with which they are assembled. For example, an archetypal lecture theatre is made to be assembled with didactic presentations, from the placement of seats to that of the blackboard, whiteboard, or projection screen. It assumes the lecturer to be in control of activities, and deliberately separates the learners from the teacher. It also tends to make alternative pedagogical methods to the lecture or demonstration relatively difficult to achieve. Inventive teachers or students typically need to assemble the lecture hall with pedagogies that overcome some of its limitations, such as pyramiding, goldfish-bowls, use of clickers, or other techniques and tools to augment or partially replace some of its harder elements. The system is made softer, but thus demands greater effort and skill to implement. Unsurprisingly, because they replicate the patterns of traditional education, similar issues affect learning management 
systems (LMSs). The tools they provide are mostly designed for teachers to control, replicating didactic teaching through content-creation tools, testing through 'objective' tests, discussion through discussion forums, and so on. Like the lecture theatre, most LMSs can be bent to many pedagogical purposes by assembling them with appropriate methods. However, like the lecture theatre, the easiest (and most likely to be taken) paths are those that replicate classroom practices that have barely changed since mediaeval times, to which we turn next.

\section{Are traditional learning environments smart?}

The problems that the earliest mediaeval higher education institutions like the Universities of Paris and Bologna sought to solve were mainly related to a need to transmit doctrine and related knowledge, held by a few scholars, to a larger number of students. Lectures were a relatively efficient and cost-effective means to convey (at least to highly motivated students) the ideas and thinking of the sages, whether directly or through readings from original texts or glosses. The origin of the word 'lecturer' is one who reads, a necessity in days before printing made books more affordable. Class sizes were determined largely by how far the human voice could carry. Lecturers needed to be heard, so talking among students had to be discouraged while the lecturer was speaking, and one lecturer had to face the whole class, contributing to a very unequal power relationship. This was cemented by the fact that lecturers were expected to fill - and be in control of - every second of the entire duration of a lesson. There was no point in lecturing when no one was there, so classes had to occur at more or less specific times, for more or less specific durations, and lectures only occurred when there were no public holidays, or when students did not have to be elsewhere (such as at harvest time). This led to timetables, curricula, terms and semesters, which were never pedagogically driven periods of time. They were simply pragmatic responses to student availability, but they strongly dictated the existence, form, and length of our main motif for teaching: the course.

Once everyone was learning much the same things, assessments to compare their learning to what was taught followed naturally. Over centuries, as institutions and the value of their awards increased, it became desirable to standardize ways of measuring student success. Combined with a need to limit costs and increase scalability, this resulted directly in the graded assessment-driven systems we see today (Schneider \& Hutt, 2014). Grade-based assessment schemes and measurements of standardized outcomes were efficient and scalable ways to award credentials, given the available technologies up until the Internet age. As well as dire motivational consequences that I will discuss in the next section, the increasing significance of the role of credentialing of learning led to two quite divergent and, largely, mutually exclusive purposes for our educational systems. They had to be not only smart learning environments, but also smart credentialing environments.

Other consequences of this basic dynamic led directly to further common features of contemporary educational systems, from faculties and deans to subject areas and schools, from libraries to fraternities, from exam boards to classrooms. Educational systems as we know them today have evolved within a physical and organizational context to solve problems that were largely determined by the limits and boundaries of mediaeval scholastic systems, ratcheted by path dependencies that developed along the way that reinforced and amplified the original constraints while, especially in the area of 
accreditation, adding new ones of their own. Each new layer of complexity added new purposes to the system: for example, the presence of faculties also led to those willing to defend, sustain, and nurture them, which itself became one of the sub-purposes of the environment. The educational environments that ensued have been very successful in solving the problems they faced. However, like most technologies, solutions to one problem often created new ones. Pedagogically, the biggest price to be paid is in student motivation, to which we turn next.

\section{The innate stupidity of traditional in-person learning environments}

Early universities did not have to worry too much about the motivation of their students. Anyone willing to voluntarily take out years of their lives at considerable personal expense and discomfort in order to acquire knowledge and skills more or less had to be highly intrinsically motivated. However, as centuries went by, competition increased and, especially, as the role of educational institutions as providers of credentials became more prominent, the inevitable consequences of shifting power from students to teachers became increasingly significant.

The first problem of traditional teaching is that it embeds and reinforces the power of the teacher to control everything that happens in a classroom, at least for the duration of a lesson. Self-determination theory demonstrates that intrinsic motivation cannot emerge unless a person has a sense of autonomy (Ryan \& Deci, 2006), against which the traditional classroom model thus actively militates. This became most problematic once attendance became mandatory: even lectures remain useful in, for example, conferences, because attendance is usually voluntary and each attendee chooses their own purpose and intended outcomes.

The one-to-many nature of traditional teaching also means that, without much care in pedagogical design, in any given body of learners there will be some that are insufficiently challenged (and so are bored), and some that are over-challenged (and so are confused). This undermines another of the three prerequisites of intrinsic motivation, support for gaining competence (Deci \& Moller, 2005).

Only the third and final pillar of intrinsic motivation, support for relatedness, tends to be innately well-supported by traditional educational systems, which typically focus on providing tight-knit communities and emphasize the relationship between teacher and learner.

A large part of the essence of good teaching, in a traditional educational environment, is therefore centred around developing ways to restore the motivation that a traditional educational system removes. Unfortunately, especially when combined with credentialing, this has led to an ultimately more devastating problem: that by far the most commonplace solution to the inevitable loss of intrinsic motivation is to replace it with extrinsic motivation, usually in the form of reward and punishment (Reeve, 2009). Whether through the promise/threat of grades or explicit processes of punishment for transgressing behaviours, our schools, colleges, and universities are to a large extent driven by an extrinsic reward structure. Such rewards have typically become the primary purpose of learning, crowding out any intrinsic motivation that students may have otherwise felt. A large body of research conclusively proves that extrinsic motivation persistently replaces, rather than enhances, intrinsic motivation (Deci et al., 1999). Extrinsic motivation 'works' in the sense that it reliably achieves compliance. However, when it is taken away, intrinsic motivation 
does not return: it is almost invariably replaced with amotivation. Learners are invariably less motivated after being extrinsically driven through external regulation of their actions than before they began (Deci, 1972; Lin et al., 2003).

If our intent is to support the development of lifelong learning, or at least a persistent passion for learning, a traditional educational environment is therefore stupid. It takes a lot of skill and care on the part of teachers to alleviate at least some of the harm that results, though it is seldom possible to alleviate all the ill effects for all students. It demands ingenuity in the design of pedagogies that reintroduce greater learner autonomy (Reeve, 2006), and that provide more personalized methods that support competence, without losing the benefits of relatedness that are a strong feature of in-person teaching. Pedagogies of conventional in-person teaching thus represent solutions to problems caused by the inevitable constraints of in-person learning. They are simply our best attempts to overcome systemic weaknesses in our educational systems. We need them as part of the assembly because, otherwise, the assembly is a very stupid learning environment: one that is not just unintelligent, but that actively militates again the learning of its inhabitants.

\section{The manufactured stupidity of online learning environments}

Unfortunately, approaches such as courses, teacher-controlled activities, and the use of grades to reward or punish, that were a rational-if-imperfect solution to problems imposed by physics in traditional classrooms are, nowadays, also commonly used in online learning equivalents, despite natively suffering few of the same constraints. Indeed, in some ways, online learning is (natively) the motivational inverse of traditional institutional teaching, strong in providing control and support for competence, but weaker in supporting at least those forms of relatedness that rely on hierarchical groups. It is worthwhile to pick this apart a little further.

For those with Internet access, online learning is far more common than in-person learning. While only around a third of students in formal institutions take any online courses, at least in the US (Ortagus, 2017), billions more learning journeys start every day with a Google search, a YouTube video, a Wikipedia article, a StackExchange question, an email, or a forum posting. Even students taking formal courses are also using such tools. Online learners have orders of magnitude more choice and control than their in-person forebears, and the plethora of available resources (including skilled individuals) that the Internet makes available mean that, somewhere, there will always be learning activities and resources that match any individual's current needs to attain competence. This is notwithstanding the fact that it may be difficult to find them, and even harder to ascertain their reliability.

Relatedness is also well catered-for, though is singularly less well achieved in most formal online courses. It is not that online relationships are any less intense in principle, but that the kinds of relationship that have most value in conventional in-person pedagogies - especially those relying on hierarchical roles - are much harder to achieve in an online setting. The in-person classroom is the learning environment, and therefore can be controlled. The fact that online systems are only ever part of a learner's learning environment means that learners innately have greater agency. Combined with the lack of personal presence that tends to emerge from a paucity of communication cues, it tends to be 
difficult or impossible to maintain authority - at least of the kind common and necessary in many classroom settings - in an online environment. Those that none-the-less attempt to use classroom pedagogies consequently tend to fall back heavily on the main piece of leverage that remains at their disposal once the innate power dynamics of a physical classroom are removed: the rewards and punishments of assessment. It is not surprising that many find online learning an unattractive option.

While rates of failure to start a course generally tend to be higher in formal online learning than in traditional in-person learning, the effect may be seen most starkly in settings in which the threats, rewards, and punishments are almost entirely removed, such as in most MOOCs (massive open online courses). Until quite recently, MOOC completion rates averaged around 6.5\% (Jordan, 2014). The problem is down to the use of courses in the first place, which were a design solution to physical exigencies, not an innately good way to learn. It is telling that these rates have (from the point of view of providers) improved in recent years, due almost entirely to premium-priced credentials, thanks to which completion rates now hover closer to 15\% (Jordan, 2016).

When assembled with traditional in-person teaching, online learning can be relatively beneficial to motivation, aggregating the benefits of any-time, any-place, flexible-pace learning with the relatedness support of traditional in-person teaching. Blended, hybrid, or flipped pedagogical designs that attempt to gain the best of both worlds tend to have marginally better overall outcomes than either online or in-person learning (Means et al., 2013; Tamim et al., 2011). This is perhaps because of the increased autonomy and support for competence that they offer, perhaps due to the softening that online elements provide, perhaps simply due to a greater attention to pedagogy implied by their use - but only when assembled with the rules of mediaeval teaching systems. This is an incremental improvement, not a solution to the central problem.

\section{Smarter learning environments: Connectivist models}

Most pedagogical models that evolved through the twentieth Century were primarily focused on making learning more effective or efficient within a conventional classroom setting. Instructivist models - based on behaviourist and cognitivist theories that focus on ways to support the learning of an individual and that assume a fixed, objective, measurable set of outcomes -fit well within a classroom context, supporting the teacher as arbiter, sage, and guide. Constructivist and social constructivist models, though based on theories of learning rather than theories of teaching, and though inherently softer, were similarly adapted to a teacher-controlled context. Though constructivist epistemology sees knowledge as either inherently constructed by an individual, or through a process of dialogue and interaction within a community, its instantiations within educational systems almost always involve the teacher in leading and directing the process, typically with a (teacher-created) set of learning goals and outcomes driving the process.

A new family of theories and models for learning were developed during the 1990s and 2000s, largely in response to the increase of adjacent possibilities afforded by the growth of the Web. Anderson \& Dron (2011) have characterized this as the connectivist generation of pedagogies. Among the theories' and models' shared foundations are:

- that the problems to solve are not, as in mediaeval times, a paucity of resources but a surplus; 
- that learning (and, by extension, teaching) resides not just in individual people but in non-human entities, from simple web pages, to AI entities, to emergent behaviours of networked systems;

- that learning in this context is primarily a process of connection more than construction or absorption, of knowing where to find knowledge and skills;

- that learning is a process of creation, best enabled when creations are shared;

- that learning should be both innately personal (controlled by the learner) and innately social (performed with, for and through others);

- that a sufficiently large network of learners can, in combination, be better, more personalized, and more flexible teachers than individual teachers themselves (recursively, of course, such networks typically include those who identify as teachers).

Though several inspirations and close analogues can be found in earlier theories of pre-networked learning, such as Andragogy (Knowles, 1975), Distributed Cognition (Pea, 1993), and Communities of Practice (Wenger, 1998), the bulk of theories and models in this family relate explicitly to online or technology-enhanced learning. They include the eponymous Connectivism itself (Downes, 2008; Siemens, 2005), Heutagogy (Hase \& Kenyon, 2007), Networks of Practice (Wenger et al., 2011), Rhizomatic Learning (Cormier, 2008), and Transactional Control (Dron, 2007).

Connectivist models or theories treat the learner's environment as unique to that learner, largely under their control, but at the same time deeply and indivisibly social, formed by and embedded within a network of connections. This is networked individualism (Wellman, 2002) writ large. Unlike the traditional hierarchical, teacher-controlled, scheduled, planned, goal-driven groups of traditional education, networks are by definition centred around nodes (individuals), and are different for every learner (Dron \& Anderson, 2014). Teacher-like roles - didactic, supportive, role-modelling, and so on - are played by other nodes of the network, including the non-human, but most prominently by the learners themselves. The central skill of connectivist era learners is that of sense-making: of being able to discern patterns, make connections, filter out the useless, organize the useful, find meaning in the plethora of knowledge flowing through the network. Networked learners are not working alone there may be many ways they are helped by, inspired by, and guided by others, including digital systems - but they are on a personal learning journey. A smart connectivist learning environment is not one that guides a learner to a predetermined destination, but one that is responsive, that challenges, engages, reflects back, and connects a learner with a network. What makes it smart is that, in adapting to the environment, learners play an active role in changing it (for themselves and others) and, in the process, they learn themselves.

Connectivist learning environments are smart learning environments because of networks of people more than of smart machines. However, sensemaking in connectivist environments is typically supported through the use of aggregation tools, such as news feed readers and social bookmarking systems, that help to pull together and make sense of the firehose of information that networked learners must deal with and that enable sharing of those aggregations and annotations with others, as well as other tools that support the organization of knowledge, from mind mapping tools to blogs. Such tools form part of each learner's personal learning environment (PLE) (Attwell, 2007; Wilson et al., 2007). It 
should be noted, though, that must be assembled by individuals, not for individuals. In the late 2000s and early 2010s a large number of systems were built that described themselves as PLEs but were, at best, simply components of one and, in some cases, sought to actively control learners through filtering, sequencing, and sorting algorithms. The term's value consequently became significantly diluted and diminished. An effective PLE that both draws from and gives back to a broader network is, almost by definition, a smart learning environment.

\section{Designing learning environments within formal educational systems that are not stupid}

Although traditional classes and their outputs can be among the components of the connectivist learner's environment, they cannot and do not form or structure that environment. While connectivist models are very useful from the perspective of individual learners, they fit uneasily within the teacher-controlled environments of institutional learning. There are, none-the-less, several ways to make such environments smarter:

\section{Let go}

Anything we design is only ever going to be a part of the overall learning environment of the student. Teachers and learning designers who seek to support smart learning environments must let go of our illusions of control because we cannot ever actually possess it. This implies a need to make it beneficial for learners to share their findings with one another, to personalize their own learning (not to attempt to personalize it for them). Adaptive technologies have a place, but only when they are descriptive, not prescriptive: we need systems that advise, rather than systems that try to dictate a learning path. We should provide assemblable pieces rather than engineered complete solutions. The online or augmented technology environments we build should become part of the learners' PLEs as easily as possible, through pedagogical design and through technological standards. It is better to design smart devices according to the distributed rather than the centralized model, because it increases the potential for assembly. Open standards such as RSS/Atom, xAPI, Caliper, LTI, HTML5, and so on should be embraced, and proprietary formats should be eschewed, because they are less capable of assembly. Alternative methods of assessment that provide greater learner control such as mastery learning, contract grading, pass/fail marking (Schneider \& Hutt, 2014), portfolios, challenge processes, and competence-based techniques should be used to decouple credentialing from the learning process, and thus limit extrinsic drivers to learning.

\section{Critically analyze the boundaries}

Many of our most basic units of traditional educational systems - courses, lessons, classes, cohorts, exams, and so on - are a consequence of contingent factors. They are not fundamental to learning, and their very existence affects the range of potential pedagogies that can be used. Where possible, we should question and, if necessary, dismantle the artificial boundaries they create. We should, if possible, create opportunities to share across class and cohort boundaries, to allow persistence in access, and in the products of learning, to offer alternative forms of assessment, to make it easier for learners to participate in the design of their own learning. 


\section{Assemble to soften or harden}

Pedagogies are like any technologies - assemblies of other technologies - and it is the assembly that matters most, rather than the technologies that constitute that assembly. There are always countless other ways to solve the problems, some of which might (in the right assembly) be better in a given context. It is unlikely that we will be able to give serious consideration to more than a tiny fraction of these, but it is almost certain that somewhere among the billions of connected nodes of the Internet (or even in a conventional library) someone has done so. Finding alternatives is a job for all learners, teachers, friends and family - not the sacred domain of the teacher. Again, we must learn to let go.

\section{It ain't what you do, it's the way that you do it}

An environment is not just a combination of technologies and structures. Just as some musicians can make great music using a poor instrument and limited technique, a great pedagogue can help to make wonderful learning happen using even the poorest of methods. There are few among us that have not at some point been transformed by a lecture, even though we have long known that lectures (when obligatory and when it is assumed they should teach what teachers intend them to teach) are among the poorest of learning technologies (Bligh, 1998; Greene, 1928). Pedagogies, and learning environments that use them, are very soft technologies that are always orchestrated anew by their users. Part of letting go is to accept that imperfect methods can engender great learning, and vice versa. Another is to realize that one of our roles is to help connect students with greater (or at least different) artists than ourselves. Another is to create conditions in which students, and other teachers, can communicate and connect: to make environments more human, with more opportunities to engage with other humans and create solutions themselves.

\section{Build to connect}

Given that our students are going to assemble their own learning environments, anything we can do to allow students to meaningfully aggregate people, objects, events, and systems into their own environment expands their adjacent possible. As we have seen, softness makes things more difficult in many ways, because it demands that choices be made, so it remains a useful teacher role to support learners in making those choices - not to make them on their behalves, but to assist them when quality criteria and eventual outcomes may not be obvious to them, and to model how we make such choices. Making it easy for students to connect with other learners, other experts, alternative resources, and so on gives them control in two ways. In the first place it provides choices, which are a prerequisite of control. In the second place, and just as importantly, it empowers learners to make wise choices.

\section{Decouple credentials and learning}

In the overall ecosystem in which our institutions sit it is often impossible to escape from the demands of professional bodies and others that expect students to have taken accredited tests of their competence. However, it is not necessary for the resulting credentials to be tightly bound to the learning process, and harmful to motivation to make 
them so. Removing the teacher-dominated driver of grades and final marks relieves the students of the extrinsic pressure to perform, allowing them to take the time they need, and to use the methods that suit them best, in order to reach a sufficient level of competence to overcome whatever hurdles they may have to face. By giving students control over what they learn, when they learn it, with whom, with what tools, in what environment, over what period and at what pace, it becomes possible for them to regain at least much of the motivation that traditional institutional learning takes away. This is far from impossible - we already often do this for things like projects, dissertations, theses, and so on. It remains, of course, vital and intrinsic to the task to give useful feedback on the learning process.

\section{Conclusion}

A smart learning environment is a personalized learning environment that contains multiple intelligent inhabitants (human and otherwise), who are themselves part of a shared environment, and who thus constitute part of the environment for one another. All environments of sufficient complexity demand that their inhabitants must adapt to them. As Churchill (Churchill, 1943) put it, we shape our dwellings and afterwards our dwellings shape our lives. A smart learning environment is one in which the main criterion for adaptational success is successful learning.

It is possible for almost any learning environment to be smart, regardless of its use of digital or other tools, if it can be assembled in the right manner with the right components, including other human beings. Equally, it is possible for even the smartest of tools in a learning environment to be made stupid if the rest of the assembly is poorly constructed or the smartness does not support effective learning within the overall system. I have till now made the case that we must therefore consider the entire assembly in order to address such problem, but this is a slight over-simplification. Just as we may compensate for problems in the natural environment through specific smart interventions (for instance, by seeding clouds, introducing new or lost species, culling over-abundant populations, or damming rivers), so we can make precision interventions in environments that are causing ill effects to compensate for their failings. Indeed, traditional active pedagogies are an example of exactly this kind of intervention. Faced with a system that militates against intrinsic motivation, teachers have developed technologies (primarily in the form of techniques and strategies) that attempt to restore motivation or to mitigate the most harmful effects. There is much to be said for digital technologies, in combination with methods and techniques, that can do the same. However, there is also reason for caution. Educational systems and, indeed, even the paths of individual learners, are complex systems that display great sensitivity to initial conditions and, equally, great resilience to major perturbance. Simply making changes in one part of the system may not have the desired effect, or may lead to undesirable perturbations elsewhere in the system. For instance, introducing a smart tutoring system might well improve the ability of a student to meet a set of required learning outcomes but, at the same time, actively reduce their sense of agency and belongingness by (for example) reducing engagement with other students, reducing their capacity to diverge from the required path, or through inadvertent errors in design such as displaying inappropriate rewards or badges that emphasize the control of the software rather than the student. Perhaps worse, if the purpose of the smart tutoring system is (or can 
be perceived as being) to prepare students for a test or qualification, it may reinforce the power structures that are so damaging in the first place.

Apart from in limited cases - primarily, in-person teaching in formal institutions learning environments can be seen as smart only in relation to specific individual learners, because every learner's environment differs from every other. Smartness for one may be stupidity for another. However, they are seldom if ever concerned solely with individual learning. Education is not just about learning facts and skills, but is at its heart about learning how to be human within a society of humans. This is one of the reasons that, though adaptive systems and intelligent agents might play useful roles in smart learning environments, we are a long way from a time when other humans are no longer needed in them: the most fruitful roles for them are to make it easier to connect with one another, and to add richness to those connections. Smart learning environments are as much places that channel (and that are shaped by) communities of learners, that adapt (and that are adapted to) both by and for networks and groups of inhabitants, as they are places for individual learners to discover knowledge and skills. It would be deeply worrying to delegate the task of welcoming someone into that community to a machine, at least until such a time as we welcome machines into our social communities as equals. However, digital tools can, with care, help us to connect more usefully, reliably, and promptly, as long as they integrate with a whole that supports learning effectively. In the bigger picture, the smartest learning environments are inhabited spaces that provide the richest opportunities for people to connect, engage, support, and challenge one another to learn.

Acknowledgements

I wish to thank Athabasca University for providing me with the time and flexibility to write this paper.

Author's contributions

Entire paper. The author read and approved the final manuscript.

Competing interests

The author declares that he/she has no competing interests.

\section{Publisher's Note}

Springer Nature remains neutral with regard to jurisdictional claims in published maps and institutional affiliations.

Received: 18 July 2018 Accepted: 8 October 2018

Published online: 19 October 2018

References

T. Anderson, J. Dron, Three generations of distance education pedagogy. Int. Rev. Res. Open Dist. Learn. 12(3) (2011) Retrieved from http://www.irrodl.org/index.php/irrodl/article/view/890

W.B. Arthur, The Nature of Technology: what it is and how it evolves (Kindle ed.) (Free Press, New York, USA, 2009)

G. Attwell, Personal learning environments-the future of eLearning? eLearning Papers 2(1), 1-7 (2007)

D.A. Bligh, What's the Use of Lectures? (Intellect, Exeter, 1998)

B.S. Bloom, The 2 sigma problem: The search for methods of group instruction as effective as one-to-one tutoring. Educ. Res. 13(6), 4-16 (1984) Retrieved from http://www.jstor.org/stable/1175554

P. Checkland, Soft systems methodology: A thirty year retrospective. Syst. Res. Behav. Sci. 17, 11-58 (2000)

Churchill, W. (1943). HC Deb 28 October 1943 Vol 393 c403. Retrieved from https://api.parliament.uk/historic-hansard/ commons/1943/oct/28/house-of-commons-rebuilding

C.M. Cipolla, The Basic Laws of Human Stupidity (Società editrice II Mulino, Bologna, 2011)

A. Clark, Supersizing the Mind: Embodiment, Action, and Cognitive Extension: Embodiment, Action, and Cognitive Extension (Oxford University Press, 2008)

Cormier, D. (2008). Rhizomatic education: Community as curriculum. Innovate J. Online Educ., 4(5), 2

E.L. Deci, The effects of contingent and noncontingent rewards and controls on intrinsic motivation. Organ. Behav. Hum. Perform. 8(2), 217-229 (1972). https://doi.org/10.1016/0030-5073(72)90047-5

E.L. Deci, R. Koestner, R.M. Ryan, A meta-analytic review of experiments examining the effects of extrinsic rewards on intrinsic motivation. Psychol. Bull. 125(6), 627 (1999) 
E.L. Deci, A.C. Moller, in Handbook of Competence and Motivation, ed. by A. J. Elliot, C. S. Dweck. The concept of competence: A starting place for understanding intrinsic motivation and self-determined extrinsic motivation (The Guilford Press, New York, 2005), pp. 579-597

S. Downes, Places to go: Connectivism \& Connective Knowledge. Innovate 5(1) (2008) Retrieved from https:// nsuworks.nova.edu/innovate/vol5/iss1/6/

J. Dron, Control and Constraint in E-Learning: Choosing when to Choose (Idea Group International, Hershey, PA, 2007)

J. Dron, Soft is hard and hard is easy: Learning technologies and social media. Form@re 13(1), 32-43 (2013) Retrieved from http://www.fupress.net/index.php/formare/article/view/12613

J. Dron, T. Anderson, Teaching Crowds: Learning \& Social Media (AU Press, Athabasca, 2014) Retrieved from http://teachingcrowds.ca

R.D. Fields, Making memories stick. Sci. Am. 292(2), 75-81 (2005)

U.M. Franklin, The Real World of Technology (Kindle ed.) (House of Anansi Press, Concord ON, 1999)

J.J. Gibson, in Perceiving, Acting, and Knowing: Toward an Ecological Psychology, ed. by R. Shaw, J. Bransford. The theory of affordances (Lawrence Erlbaum, Hillsdale, NJ, 1977), pp. 67-82

B. Goertzel, Artificial general intelligence: Concept, state of the art, and future prospects. J. Artif. General Int. 5(1), 1-48 (2014)

E.B. Greene, The Relative Effectiveness of Lecture and Individual Reading as Methods of College Teaching. Genet. Psychol. Monogr. 4, 459-563 (1928)

H. Gwo-Jen, S. Yen-Ru, C. Hui-Chun, A concept map approach to developing collaborative Mindtools for contextaware ubiquitous learning. Br. J. Educ. Technol. 42(5), 778-789 (2011). https://doi.org/10.1111/j.1467-8535. 2010.01102.x

S. Hase, C. Kenyon, Heutagogy: A child of complexity theory. Complicity Int. J. Complex. Educ. 4(1), 111-118 (2007) Retrieved from Retrieved March 2008 from https:/journals.library.ualberta.ca/complicity/index.php/complicity/article/view/8766/7086

G.-J. Hwang, Definition, framework and research issues of smart learning environments - a context-aware ubiquitous learning perspective. Smart Learn. Environ. 1, 4 (2014). https://doi.org/10.1186/s40561-014-0004-5

K. Jordan, Initial trends in enrolment and completion of massive open online courses. Int. Rev. Res. Open Distr. Learn. 15(1) (2014)

Jordan, K. (2016). MOOC Completion Rates: The Data. Retrieved 31 May 2016, from http://www.katyjordan.com/MOOCproject.html

S. Kauffman, Investigations (Kindle ed.) (Oxford University Press, New York, 2000)

K. Kelly, What Technology Wants (Kindle ed.) (Viking, New York, 2010)

M. Knowles, Self-Directed Learning (Follett Publishing Company, Chicago, 1975)

R. Koper, Conditions for effective smart learning environments. Smart Learn. Environ. 1, 5 (2014)

Y.G. Lin, W.J. McKeachie, Y.C. Kim, College student intrinsic and/or extrinsic motivation and learning. Learn. Individ. Differ. 13(3), 251-258 (2003)

C. Lu, M. Chang, D. Kinshuk, E. Huang, C.-W. Chen, Usability of context-aware mobile educational game. Knowl. Manag. e-Learning Int. J. (KM\&EL) 3, 448-477 (2011)

B. Means, Y. Toyama, R. Murphy, M. Baki, The effectiveness of online and blended learning: A meta-analysis of the empirical literature. Teach. Coll. Rec. 115(3), 1-47 (2013)

D.A. Norman, Cognitive artifacts. Designing interaction: Psychology at the human-computer. interface 1, 17-38 (1991)

J.C. Ortagus, From the periphery to prominence: An examination of the changing profile of online students in American higher education. Internet High. Educ. 32, 47-57 (2017). https://doi.org/10.1016/j.iheduc.2016.09.002

R.D. Pea, Practices of distributed intelligence and designs for education. Distr. Cogn. Psychol. Educ. Consider. 11, 47-87 (1993)

M.S. Raisinghani, A. Benoit, J. Ding, M. Gomez, K. Gupta, V. Gusila, D. Power, O. Schmedding, Ambient Intelligence: Changing Forms of Human-Computer Interaction and their Social Implications. J. Digit. Inf. 5, 4 (2006) (2004): Social Aspects of Digital Information in Perspective. Retrieved from https://journals.tdl.org/jodi/index.php/jodi/ article/view/149

Reeve, J. (2006). Teachers as facilitators: What autonomy-supportive teachers do and why their students benefit. Elem. Sch. J." 106(3), 225-236. Retrieved from file://C:\%5CDocuments\%20and\%20Settings\%5Cmhartnet\%5CMy\%20Documents\%5CStud y\%5CPhD\%5CLiterature\%5CSDT\%5CTeachers\%20as\%20facilitators\%20what\%20autonomy\%20supportive\%20teachers\%20 do\%20and\%20why\%20their\%20students\%20benefit.pdf

J. Reeve, Why teachers adopt a controlling motivating style toward students and how they can become more autonomy supportive. Educ. Psychol. 44(3), 159-175 (2009) Retrieved from https://www.tandfonline.com/doi/full/10.1080/ 00461520903028990

R.M. Ryan, E.L. Deci, Self-regulation and the problem of human autonomy: Does psychology need choice, self-determination, and will? J. Pers. 74(6), 1557-1585 (2006)

J. Schneider, E. Hutt, Making the grade: A history of the A-F marking scheme. J. Curric. Stud. 46(2), 201-224 (2014). https:// doi.org/10.1080/00220272.2013.790480

G. Siemens, Connectivism: a learning theory for the digital age. Int. J. Instruct. Technol. Distance Learn. 2(1) (2005) Retrieved from http://www.itdl.org/journal/jan_05/article01.htm

J.M. Spector, Conceptualizing the emerging field of smart learning environments. Smart Learn. Environ 1, 2 (2014)

R.M. Tamim, R.M. Bernard, E. Borokhovski, P.C. Abrami, R.F. Schmid, What forty years of research says about the impact of technology on learning. Rev. Educ. Res. 81(1), 4-28 (2011). https://doi.org/10.3102/0034654310393361

S. Turkle, Alone Together (Basic Books, New York, 2011)

M. Weiser, R. Gold, J.S. Brown, The origins of ubiquitous computing research at PARC in the late 1980s. IBM Syst. J. 38(4), 693-696 (1999). https://doi.org/10.1147/sj.384.0693

B. Wellman, in Digital Cities II: Second Kyoto Workshop: Revised Papers, ed. by M. Tanabe, P. van den Besselaar, T. Ishida. Little boxes, glocalization and networked individualism (Springer, Retrieved from From, 2002) http://groups.chass.utoronto.ca/ netlab/wp-content/uploads/2012/05/Little-Boxes-Glocalization-and-Networked-Individualism.pdf

E. Wenger, Communities of Practice: Learning, Meaning and Identity (Cambridge University Press, New York, 1998)

E. Wenger, B. Trayner, M. de Laat, Promoting and Assessing Value Creation in Communities and Networks: A Conceptual Framework (Ruud de Moor Centrum, The Netherlands, 2011) 
S. Wilson, O. Liber, M. Johnson, P. Beauvoir, P. Sharples, C. Milligan, Personal learning environments: Challenging the dominant design of educational systems. J. e-Learning Knowl. Soc. 3(2), 27-38 (2007) Retrieved from http://ubir.bolton.ac uk/289/1/iec_journalspr-9.pdf

S. Wu, A. Chang, M. Chang, Y.R. Yen, J.S. Heh, Learning Historical and Cultural Contents via Mobile Treasure Hunting in FiveHarbor District of Tainan (Proceedings from 2010 6th IEEE International Conference on Wireless, Mobile, and Ubiquitous Technologies in Education, Taiwan, 2010)

Submit your manuscript to a SpringerOpen ${ }^{0}$ journal and benefit from:

- Convenient online submission

- Rigorous peer review

- Open access: articles freely available online

High visibility within the field

- Retaining the copyright to your article

Submit your next manuscript at $\boldsymbol{\nabla}$ springeropen.com 